\title{
Desempenho de novilhos de origem leiteira na pecuária de corte em diferentes sistemas de criação: Revisão
}

\author{
Rodrigo da Silva Lima ${ }^{1 *}$, José Almir Ferreira Gomes ${ }^{1}$, Edmilson Gomes da Silva ${ }^{1}$, Thiciano Leão \\ Miranda $^{1}$, Rafael Santos de Aquino ${ }^{2}$, Almir Ferreira da Silva ${ }^{3}$ \\ ${ }^{I}$ Professores do Instituto Federal de Educação, Ciência e Tecnologia do Sertão Pernambucano/Campus \\ Salgueiro \\ ${ }^{2}$ Professor do Instituto Federal de Educação, Ciência e Tecnologia do Sertão Pernambucano/Campus Ouricuri; \\ ${ }^{3}$ Zootecnista. \\ *Autor para correspondência, E-mail: rodrigo.lima@ifsertao-pe.edu.br
}

\begin{abstract}
RESUMO. A bovinocultura leiteira no Brasil tem crescido muito nos últimos anos, tanto em número de animais quanto em produtividade. Contudo, uma dificuldade real é dar um destino adequado aos bezerros machos que nascem nessas propriedades, já que há um maior interesse em criar e recriar bezerras fêmeas para serem as futuras matrizes do rebanho. Nos últimos anos esses bezerros têm sido estudados com relação a sua potencialidade de serem aproveitados na pecuária de corte, o que seria uma possível forma de gerar renda a partir do aproveitamento desses animais, e não descarta-los abatendo ou doando a outras propriedades como é feito atualmente pelas propriedades leiteiras. Vários trabalhos têm verificado que esses animais leiteiros podem sim serem aproveitados na pecuária de corte tanto em sistemas de produção em pastejo como também em confinamento, contudo, é claro, sem esperar que apresentem o mesmo desempenho produtivo que animais especializados para produção de carne apresentam. Os trabalhos realizados evidenciam que a viabilidade de utilizar esses animais de origem leiteira para produção de carne depende das condições de se conseguir abates precoces e uma produção a baixo custo, sendo esses fatores intrínsecos a cada sistema de produção.
\end{abstract}

Palavras chave: Bezerros, bovinocultura leiteira, ganho em peso.

\section{Performance of steers of dairy origin in beef cattle in different production systems: Review}

\begin{abstract}
The dairy cattle in Brazil has grown tremendously in recent years, both in number of animals and in productivity. However, a real difficulty is to give suitable male calves born on these properties, since there is a greater interest in creating and recreating female calves to be future mothers of the herd destination. In recent years these calves have been studied in relation to its potential to be utilized in beef cattle, which would be a possible way to generate income from the exploitation of these animals, and would not rule them slaughtering or donating to other property as is currently done by dairy farms . Several studies have found that these dairy animals but can be availed in beef cattle production systems in both grazing as well as in confinement, however, of course , without waiting to have the same performance than specialized animals for meat production feature. The work carried out show that the feasibility of using these animals of dairy origin for meat production depends on the conditions to achieve early slaughter and a low cost production, these being intrinsic to each system of production factors.
\end{abstract}

Key-words: Calves, dairy cattle, weight gain

\section{Introdução}

No atual cenário mundial da produção de alimentos, o Brasil é considerado como um dos principais países que apresentam grandes potencialidades na produção de gêneros alimentícios, tanto de produtos de origem animal como vegetal (FAPRI, 2015). Desta forma, são vários os investimentos neste setor a fim de aumentar a eficiência produtiva assim como aproveitar todos os recursos que podem ser 
utilizados na produção de alimentos. Neste contexto, torna-se importante o aproveitamento de todos os produtos gerados nas cadeias produtivas para que desta forma se consiga a viabilidade do sistema e a sustentabilidade do empreendimento. Assim, esta revisão buscou verificar o desempenho de novilhos de origem leiteira utilizados para produção de carne, tendo em vista a crescente oferta desses animais nas propriedades leiteiras.

\section{Variáveis que influenciam o desempenho em novilhos de origem leiteira}

O tipo bovino utilizado para produção de carne no Brasil, os animais especializados oriundos de décadas de seleção possuem destaque na cadeia produtiva da carne bovina. No entanto, com o incremento cada vez maior da bovinocultura leiteira nacional, cresce cada vez mais a oferta de bezerros filhos dessas vacas, sendo a produção de leite a principal renda da propriedade.

Na cadeia produtiva do leite, a especialização da produção torna-se cada vez mais necessária para a sobrevivência e sustentabilidade dos empreendimentos pecuários. Assim, com relação a produção de bezerros que não contribuem para a produção de leite, exceção feita aos machos geneticamente superiores selecionados para a reprodução, torna-se necessário dar um destino adequado a esses animais de forma que gere uma renda suficiente para cobrir seus custos e ainda proporcionar lucro a propriedade rural. Neste contexto, uma das possibilidades e necessidades, seria o desenvolvimento de tecnologias e metodologias que viabilizassem a utilização destes animais de origem leiteira para produção de carne, garantindo assim, maior lucratividade e aproveitamento da cadeia produtiva como um todo.

Para Rocha et al. (1999), (Jorge et al., 2002a, Jorge et al., 2009) o potencial para corte, de bezerros de raças leiteiras de grande porte, especialmente a holandesa e seus mestiços, tem sido avaliadas em inúmeras pesquisas no Brasil e no exterior, sendo que a utilização desses animais para produção de carne já vem ocorrendo a bastante tempo. Tyler (1970) ressaltava que já naquela época esses animais já eram utilizados para produção de carne nos Estados Unidos e países Europeus, como por exemplo, na Alemanha, Holanda e França (Prado et al., 1989b, Prado et al., 1989a).
No Brasil, no censo agropecuário realizado pelo Instituto Brasileiro de Geografia e Estatística (IBGE, 2013) foi contabilizado um plantel de mais de 12 milhões de vacas leiteiras, o que demonstra a grande oferta de bezerros de origem leiteira e a grande necessidade de seu aproveitamento na pecuária de corte.

Assim, devido à importância do aproveitamento desses animais, a sua exploração econômica deve ser desenvolvida e fundamentada em uma série de estratégias que visem aumentar o ganho em peso, sem, contudo, onerar o custo de sua criação. Para Bomfim (2000), (Jorge et al., 2002a, Jorge et al., 2002b), o aproveitamento do macho leiteiro assume grande importância devido a aquisição de animais ser um fator econômico de grande peso (70 a $80 \%$ do custo total) sendo o preço do animal para a engorda um fator decisivo para a viabilidade do sistema produtivo.

No Brasil, esses machos provenientes de plantéis especializados na produção de leite, com predominância de genética européia, principalmente da raça holandesa, usualmente são eliminados logo ao nascimento e representam grande desperdício para os produtores que trabalham com maiores custos de produção. $\mathrm{O}$ descarte desses animais decorre das dificuldades impostas à sua criação pelas suas elevadas exigências em nutrição, sanidade e conforto (Almeida Júnior et al., 2008).

Assim, os cruzamentos entre raças zebuínas e europeias têm proporcionado à pecuária de corte nacional os benefícios do vigor híbrido, com incremento da produtividade do rebanho (Rocha Júnior et al., 2010). Esses cruzamentos entre zebu e raças europeias têm sido bastante utilizados na pecuária de corte, sobretudo cruzamentos com raças especializadas na produção de carne (Rotta et al., 2009). No entanto, em sistemas mistos, devido à presença de elevada quantidade de material genético de raças de origem leiteira, também já se utiliza os cruzamentos entre essas raças tipicamente leiteiras com os zebuínos a fim de melhorar a adaptabilidade dos animais de origem européia ao ambiente tropical com consequente melhor desempenho em ganho em peso.

São vários os fatores que podem influenciar o desempenho dos machos de origem leiteira destinada à produção de carne, dentre eles temos o regime nutricional adotado, a composição genética Holandês/Zebu, o sistema de produção 
utilizado e características relacionadas à sanidade animal. Os bezerros de origem leiteira, geralmente, recebem os piores manejos na propriedade, deixando às melhores condições, principalmente nutricionais, as fêmeas que serão as futuras matrizes e geradoras de renda para a propriedade rural. Para Rocha et al. (1999) as restrições alimentares normalmente impostas aos animais de origem leiteira na fase de cria podem ter reflexos em seu desempenho posterior, como animais de abate. Essa privação alimentar, logo no período inicial do desenvolvimento corporal, pode comprometer o desempenho futuro e sua viabilidade na utilização na pecuária de corte.

Para (Perotto et al., 2000) o objetivo maior de quem se dedica a fase de cria de bovinos deve ser o de investir recursos financeiros suficientes para aplicar tecnologias que garantam o desmame de um bezerro pesado e saudável. Estes autores citam que tais tecnologias compreendem um manejo adequado, principalmente do ponto de vista nutricional; o planejamento alimentar das diferentes categorias envolvidas; a execução dos métodos de aleitamento e formas de desmame; a utilização de métodos de suplementação para os bezerros, como os creep feeding e creep grazing e o manejo e a escrituração zootécnica de maneira a se ter o controle total do sistema produtivo e dos custos envolvidos na produção.

Já com relação à composição genética da maioria dos novilhos de origem leiteira que compõem o rebanho nacional, são animais mestiços sem raça definida, normalmente de raças europeias especializadas na produção de leite (em sua maioria Holandesa) e raças zebuínas (Gir e o Guzerá), também com aptidão para produção de leite (Bomfim, 2000).

A composição genética Holandês/Zebu é um dos fatores que interferem no ganho em peso dos novilhos, sendo alvo de estudos (Rodrigues Filho et al., 2003, Melo et al., 2006, Fontes et al., 2007, Rocha Júnior et al., 2010) que compararam o desempenho em ganho em peso e outras características em animais com variada composição genética e diferentes sistemas de criação.

$\mathrm{O}$ cruzamento entre raças especializadas na produção de leite, como a holandesa, e raças menos especializadas, como a Gir, mas também com aptidão leiteira, originam animais mestiços com boa capacidade de produção de leite, mas também com bom desempenho em ganho em peso. Além de uma boa conformação da carcaça, a raça Gir, por ser mais rústica que a Holandesa, promove em animais cruzados Holandês/Gir uma maior tolerância as condições tropicais, possibilitando uma melhor adaptação e desempenho em variados regimes de produção, do extensivo ao intensivo.

Euclides Filho et al. (2000) realizaram um estudo da tendência genética da raça Gir e verificaram que entre os anos de 1962 e 1994 houve um incremento de 306 gramas por dia na característica ganho em peso pós-desmama, sendo nos dias atuais, principalmente em algumas regiões, uma raça bastante utilizada para produção de carne, mas também para produção de leite, já que ainda se trata de uma raça considerada de dupla aptidão. Assim, observa-se que novilhos mestiços Holandeses vs. Zebus possuem maior capacidade de serem recriados e/ou terminados em áreas de pastagens do que novilhos Holandeses puros, o que demonstra a importância da rusticidade proveniente dos zebuínos para os animais cruzados.

\section{Desempenho em sistemas de pastejo}

Estudos realizados verificando o desempenho desses animais em pastagens indicam um bom ganho em peso sob diferentes condições de pastejo. Melo et al. (2006) verificaram o desempenho e características de carcaça de bovinos mestiços de origem leiteira em condições de pastejo, restrito ou ad libitum, no período das águas, onde encontraram valores de ganho em peso de $0,63 \mathrm{~kg} / \mathrm{dia}$ nos animais que pastejaram a vontade em uma pastagem de Brachiaria decumbens, recebendo apenas mistura mineral como suplemento, sendo considerado pelos autores um ganho satisfatório. Os valores de ganho em peso encontrados neste experimento são ainda menores do que os encontrados por Zervoudakis et al. (2001) que registraram ganho em peso de $0,89 \mathrm{~kg} /$ dia em pastagem de Brachiaria decumbens no período das águas, trabalhando com animais mestiços recebendo apenas suplementação mineral. Para os autores, o elevado ganho em peso encontrado é devido ao fato de que a pastagem de Braquiaria decumbens, a qual, além de propiciar maior consumo, também promoveu maior aporte de nutrientes para os animais submetidos ao tratamento com suplementação apenas mineral, em razão de sua boa composição química.

Erbesdobler et al. (2002) avaliaram o consumo e o ganho em peso de novilhos 3/4 Gir- 
Holandês em pastejo rotacionado de capim elefante na estação chuvosa e obtiveram um ganho em peso médio diário de $0,52 \mathrm{~kg}$ no grupo de animais que pastejavam de forma irrestrita, sendo o tratamento pastejo irrestrito superior ao tratamento pastejo restrito, provavelmente pelo maior consumo de energia metabolizável e proteína ocorrido no primeiro por consequência da maior oferta e consumo de forragem. Outro experimento foi realizado por Fontes et al. (2007) que verificaram o desempenho de novilhos mestiços Holandês vs. Gir, em pastagem de Braquiaria decumbens e obtiveram um ganho em peso diário de $0,45 \mathrm{~kg}$ nos animais que pastejavam ad libtum, sendo considerado um ganho apenas moderado pelos autores, tendo em vista que o período experimental coincidiu com o início do período chuvoso. No entanto, os autores não determinaram o consumo de forragem, assim como não realizaram composição química da forragem para determinar sua qualidade, desprezando assim, duas importantes informações para explicar o moderado ganho em peso obtido.

Porto et al. (2008) avaliaram diferentes formas de utilização do milho como suplementos para novilhos mestiços (Holandês vs. Zebu) na fase de terminação em pastagens de Braquiaria decumbens no período das águas, relatando um ganho em peso vivo médio diário de $0,92 \mathrm{~kg}$ nos animais que recebiam apenas suplementação mineral. Os animais que foram suplementados com $1 \mathrm{~kg}$ de suplemento a base de milho obtiveram um acréscimo no ganho em peso diário de $165 \mathrm{~g}$. Assim, verifica-se que muitos trabalhos já avaliaram o desempenho de novilhos mestiços de origem leiteira em condições de pastejo e bons resultados foram alcançados frente à elevada variação da composição genética dos animais e condições de pastejo.

\section{Desempenho em sistema de confinamento}

Muitos trabalhos também têm avaliado a capacidade de utilização de novilhos de origem leiteira para produção de carne em sistemas de confinamento, sendo esta, também uma prática que vem crescendo bastante na pecuária de corte, sobretudo na fase de terminação ou acabamento (Jorge et al., 2002a, Jorge et al., 2008). Nestas condições, Fontes et al. (2007) estudaram o desempenho de novilhos Holandês vs. Gir em confinamento, verificando ganho em peso vivo diário elevado $(0,96 \mathrm{~kg})$ em animais com uma composição genética mínima de 7/8 Holandês, recebendo uma dieta composta de $44 \%$ de silagem de milho e $56 \%$ de concentrado.

Desempenho ainda melhor foi encontrado por Rocha Júnior et al. (2010) que verificaram o desempenho e características de carcaça de bovinos Nelore e Mestiços (1/2 Holandês vs. 1/4 Gir vs. $1 / 4$ Nelore) terminados em confinamento durante um período de 50 dias, encontraram um ganho em peso vivo médio de $1,28 \mathrm{~kg}$ no grupo de animais mestiços, sendo que o ganho em peso encontrado não diferiu entre os grupos estudados, concluindo os autores que a composição genética dos animais confinados durante um período de 65 dias, não influenciou a característica de ganho em peso e possuem peso de carcaça satisfatória após o período de confinamento. Esse ganho em peso foi maior que os reportados por Fernandes et al. (2004) que trabalharam com animais $1 / 2$ sangue Holandês vs. Nelore e animais Nelore em terminação, encontrando ganho em peso médio diário de 0,89 e $0,98 \mathrm{~kg}$, respectivamente.

De acordo com Euclides Filho et al. (2000) a base genética pode não ter os mesmos resultados em diferentes ambientes. Assim, essa interação que ocorre entre o genótipo animal e o ambiente que ele está inserido pode ser uma das fontes de variação no desempenho animal. Outro experimento foi realizado por Rocha et al. (1999) que observaram o ganho em peso e a eficiência alimentar de novilhos de origem leiteira, encontrando um ganho em peso vivo diário de 1 $\mathrm{kg}$ nos animais abatidos aos $350 \mathrm{~kg}$ de peso vivo, recebendo uma alimentação composta de silagem de capim napier e concentrado básico na proporção de 1:1. Neste trabalho os autores ressaltam que um ganho em peso relativamente mais elevado pode ser decorrente de ganho compensatório, tendo em vista que os animais de origem leiteira utilizados neste experimento foram criados com restrição de leite e pouco concentrado na fase anterior ao experimento, condição que os predispõe ao ganho compensatório no início da fase experimental, concluindo os autores que com base no ganho em peso apresentado, no ganho de carcaça, na conversão alimentar e no rendimento de carcaça e de seus cortes básicos, os bezerros holandeses ou mestiços 7/8 e 15/16 Holandês/Zebu, alimentados basicamente com volumosos na fase de cria, apresentaram bom potencial para produção de carne, em confinamento.

Rodrigues Filho et al. (2003) também analisaram o desempenho de novilhos de origem 
leiteira alimentados com diferentes níveis de concentrado, encontrando $0,840 \mathrm{~kg}$ de ganho em peso vivo por dia nos animais que consumiam uma alimentação composta de $50 \%$ de capim elefante e $50 \%$ de concentrado básico e $1,180 \mathrm{~kg}$ por dia no tratamento que consistia de $75 \%$ de concentrado e $25 \%$ de volumoso na dieta. Neste trabalho os autores concluíram que considerando apenas o desempenho, o confinamento de machos de origem leiteira recebendo capim elefante de boa qualidade como volumoso, a dieta com $75 \%$ de concentrado propiciou maior ganho em peso vivo, melhor conversão alimentar, e consequentemente, reduziu o tempo de confinamento.

O tempo de confinamento também deve ser levado em consideração na terminação de bovinos. De acordo com Hersom et al. (2004) quanto maior é o tempo de permanência dos animais no confinamento, menor será a eficiência do sistema produtivo. Magalhães et al. (2005) também estudando o desempenho de novilhos de origem leiteira em sistema de confinamento, obtiveram um ganho em peso médio diário de $1,27 \mathrm{~kg}$ nos animais que recebiam bem menos concentrado (40\%) a base de grão de sorgo moído e farelo de soja, onde os tratamentos consistiam na inclusão de casca de algodão na dieta. Neste trabalho foi verificado que com a inclusão de casca de algodão houve um aumento linear no consumo de matéria seca, não tendo o ganho em peso médio diário o mesmo comportamento. Provavelmente, com o aumento do consumo de matéria seca com a inclusão de casca de algodão, o conteúdo de fibra em detergente neutro (FDN) também aumentou, podendo ser um fator limitante no fornecimento de nutrientes mais digestíveis já que com o aumento da FDN os outros nutrientes diminuem proporcionalmente na dieta.

\section{Conclusão}

Os trabalhos já realizados indicam que há possibilidade de utilização de novilhos de origem leiteira na pecuária de corte, devendo ser estabelecido um sistema de criação que promova um abate precoce e a um menor custo de produção.

\section{Referências bibliográficas}

Almeida Júnior, G. A.; Costa, C.; Carvalho, S. M. R., Panichi, A. \& Júnior, P. 2008. Características de carcaças e dos componentes não-carcaça de bezerros holandeses alimentados após o desaleitamento com silagem de grãos úmidos ou grãos secos de milho ou sorgo. Revista Brasileira de Zootecnia, 37, 157-163.

Bomfim, M. A. D. 2000. Níveis de concentrado na terminação de novilhos Holandês x Zebu suplementados a pasto na estação seca. Zootecnia. Universidade Federal de Lavras, Lavras.

Erbesdobler, E. D.; FONTES, C. A. A. \& Queiroz, D. D. 2002. Avaliação do consumo e ganho de peso de novilhos em pastejo rotacionado de capim-elefante (Pennisetum purpureum, Schum.) cv. Napier, na estação chuvosa. Revista Brasileira de Zootecnia, 31, 2123-2128.

Euclides Filho, K., Silva, L. O. C.; Oliveira A, R. G. \& Figueiredo, G. R. 2000. Tendência genética na raça Gir. Pesquisa Agropecuaria Brasileira, 35, 787-791.

FAPRI. 2015. Food and Agricultural Policy Research Institute. In: Database, W. A. O. (ed.) Food and Agricultural Policy Research Institute. Iowa State University and University of Missouri-Columbia Ames, IA, USA.

Fernandes, H. J.; Paulino, M. F.; Martins, R. G. R.; Valadares Filho, S. C.; Torres, R. d. A.; Paiva, L. M. \& Moraes, G. 2004. Ganho de peso, conversão alimentar, ingestão diária de nutrientes e digestibilidade de garrotes não castrados de três grupos genéticos em recria e terminação. Revista Brasileira de Zootecnia, 33, 2403-2411.

Fontes, C. A. F.; Guimarães, R. F. M.; Izabel, M.; Vieira de Almeida, O. F. d. C.; Almeida, F. Q. \& Faria Sant'Ana, N. 2007. Avaliação do ganho compensatório em novilhos mestiços Holandês-Gir: consumo e desempenho. Revista Brasileira de Zootecnia, 36, 698-708.

Hersom, M. J.; Horn, G. W.; Krehbiel, C. R. \& Phillips, W. A. 2004. Effect of live weight gain of steers during winter grazing: I. Feedlot performance, carcass characteristics, and body composition of beef steers. Journal of Animal Science, 82, 262-272.

IBGE. 2013. Contas nacionais trimestrais. Jul.set. 2013. 20th ed. Available in: www.ibge.gov.br, Rio de Janeiro, BR.

Jorge, J. R. V.; Zeoula, L. M.; Prado, I. N. \& Geron, L. J. V. 2002a. Substituição do milho 
pela farinha de varredura (Manihot esculenta, Crantz) na ração de bezerros Holandeses. 1. Desempenho e parâmetros sangüíneos. Revista Brasileira de Zootecnia, 31, 192-204.

Jorge, J. R. V.; Zeoula, L. M.; Prado, I. N. \& Geron, L. J. V. 2002b. Substituição do milho pela farinha de varredura (Manihot esculenta, Crantz) na ração de bezerros holandeses. 2 . Digestibilidade e valor energético. Revista Brasileira de Zootecnia, 31, 205-212.

Jorge, J. R. V.; Zeoula, L. M.; Prado, I. N.; Silva, R. R.; Andrade, R. V.; Macedo, F. A. F.; Prado, J. M.; Bublitz, E. \& Marques, J. A. 2009. Gordura protegida sobre o desempenho, carcaça e composição química da carne de novilhos holandês. Archivos de Zootecnia, 58, 371-382.

Jorge, J. R. V.; Zeoula, L. M.; Prado, I. N.; Silva, R. R.; Andrade, R. V.; Prado, J. M. \& Bublitz, E. E. 2008. Lipídios em dietas para novilhos holandeses: digestibilidade aparente. Revista Brasileira de Saúde e Produção Animal, 9, 743-753.

Magalhães, K. A.; Valadares Filho, S. C.; Paulino, M. F.; Valadares, R. F. D.; Paulino, P. V. R.; Chizzotti, M. L.; Porto, M. O.; Marcondes, M. I. \& Andreatta, K. 2005. Desempenho, composição física e características da carcaça de novilhos alimentados com diferentes níveis de casca de algodão, em confinamento. Revista Brasileira de Zootecnia, 34, 2466-2474.

Melo, W. S.; Véras, A. S. C.; Ferreira, M. A.; Dutra Junior, W. M.; Andrade, D. C. B. \& Pereira, K. P. 2006. Desempenho e características de carcaça de bovinos mestiços de origem leiteira em condições de pastejo, restrito ou "ad libitum", período das águas. Revista Acta Scientiarum Animal Science, 28, 223-230.

Perotto, D.; Moletta, J. L.; Prestes, O. J. E. \& Lesskiu, C. 2000. Consumo e conversão alimentar de machos bovinos inteiros Charolês, Caracu e cruzamentos recíprocos em confinamento. Revista Brasileira de Zootecnia, 29, 108-116.

Porto, M. O.; Paulino, M. F.; Valadares Filho, S. C.; Sales, M. F. L.; Detmann, E. \& Cavali, J. 2008. Formas de utilização do milho em suplementos para novilhos na fase de terminação em pastagem no período das águas: desempenho e parâmetros nutricionais.
Revista Brasileira de Zootecnia, 37, 22512260.

Prado, I. N.; Toullec, R.; Guilloteau, P. \& Guguen, J. 1989a. Digestion de protèines de pois et de soja chez le veau preruminant. II. Digestibilité apparente à la fin d'ileon et du tube digestif. Reproduction Nutrition Development, 29, 425-439.

Prado, I. N.; Toullec, R.; Lalles, J. P.; Guguen, J. \& Hingand, H. 1989b. Digestion de protèines de pois et de soja chez le veau preruminant. I. Taux circulants de nutriments, formation d'anticorps et permeabilité intestinale aux macromolécules. Reproduction Nutrition Development, 29, 413-424.

Rocha, E. O.; Fontes, C. A. A.; Paulino, M. F. \& Ladeira, M. M. 1999. Ganho de peso, eficiência alimentar e características da carcaça de novilhos de origem leiteira. Revista Brasileira de Zootecnia, 28, 148-158.

Rocha Júnior, V. R.; Silva, F. V.; Barros, R. C. d.; Reis, S. T. d.; Costa, M. D.; Souza, A. S.; Caldeira, L. A.; Oliveira, T. S. \& Oliveira, L. L. d. S. 2010. Desempenho e características de carcaça de bovinos Nelore e Mestiços terminados em confinamento. Revista Brasileira de Saúde e Produção Animal, 11.

Rodrigues Filho, M.; Mancio, A. B.; Lana, R. P.; Roberto, P.; Cecon, F. F. d. S.; Rodrigues, N. E. B. \& Veloso, C. M. 2003. Desempenho e características de carcaça de novilhos de origem leiteira, alimentados com diferentes níveis de concentrado e de cama de frango. Revista Brasileira de Zootecnia, 32, 672-682.

Rotta, P. P.; Prado, R. M.; Prado, I. N.; Valero, M. V.; Visentainer, J. V. \& Silva, R. R. 2009. The effects of genetic groups, nutrition, finishing systems and gender of Brazilian cattle on carcass characteristics and beef composition and appearance: a review. AsianAustralasian Journal of Animal Sciences, 22, 1718-1734.

Tyler, W. J. 1970. Relationship between growth traits and production of milk and meat. Journal of Dairy Science, 53, 830-836.

Zervoudakis, J. T.; Paulino, M. F.; Detmann, E.; Lana, R. P.; Valadares Filho, S. C.; Cecon, P. R.; Queiroz, D. S. \& Moreira, A. L. 2001. Desempenho e características de carcaça de novilhos suplementados no período das águas. 
Revista Brasileira de Zootecnia, 30, 1381- License information: This is an open-access 1389.

Recebido em Outubro 3, 2014

Aceito em Março 2, 2015

article distributed under the terms of the Creative Commons Attribution License, which permits unrestricted use, distribution, and reproduction in any medium, provided the original work is properly cited. 